\title{
A composite malignant tumour of the elderly female breast
}

\author{
D. M. WAYTE, J. B. STEWART, AND C. G. McKENZIE \\ From the Royal Army Medical College, Millbank, London, and the Military Hospital, Colchester, Essex
}

SYNOPSIS A composite malignant tumour arising in the breast of an elderly woman is described. The cystic tumour containing areas of squamous metaplasia, bone formation, adenocarcinoma, and osteosarcoma was surrounded by the typical changes of mammary dysplasia (fibroadenosis).

The classification and acceptance of such tumours is highly debatable. There is no one acceptable classification of breast sarcomas and hence the prognosis of such neoplasms, particularly those containing heterologous tissues, is poorly defined. Evidence is presented in support of such composite tumours as being definite entities which arise from the closely associated epithelial and mesenchymal components of the breast simultaneously.

Sarcoma of the human breast, particularly when arising contiguously with an adenocarcinoma, remains a perplexing and controversial problem for both the surgeon and the pathologist (Hill and Stout, 1942). The great rarity of such malignant tumours and the inability to predict possible behaviour from the microscopic appearance partly account for the aura of scepticism which attends the diagnosis of a combined sarcoma and adenocarcinoma (Tudhope, 1939). There is always the doubt that the sarcomatous element is simply an undifferentiated spindle cell variant of the carcinoma (Stewart, 1950; Willis, 1958). But it is clear that the difficulties concerning the interpretation and acceptance of a combined or composite tumour can be accounted for by neglect of two basic features of mammary structure and pathology.

In the first instance it is well known that there exists a unique relationship between the epithelial component and its closely investing 'specialized' connective tissue. In the mammary dysplasia of fibroadenosis and in the benign fibroadenomata such a relationship is clearly seen. It is therefore not unreasonable to accept that on rare occasions both components may assume malignant change jointly and thereby produce the composite tumour. This argument is reinforced by the know-

Received for publication 21 October 1969. ledge that the great majority of such tumours and breast sarcomas are considered to arise from fibroadenomas (Curran and Dodge, 1962).

The second feature that is often forgotten in regard to breast pathology is the extraordinary tendency for sarcomas of the breast to undergo metaplasia resulting in the formation of heterologous tissues which include bone, cartilage, and their malignant counterparts (Jernstrom, Lindberg, and Meland, 1963; Gonzalez-Licea, Yardley, and Hartmann, 1967).

We report the present case because of the rarity of the so-called mixed or composite tumours of the breast and to outline some of the controversy that exists concerning breast sarcomas. The composite tumour reported here contained a large squamous-epithelium-lined cyst, areas of bone metaplasia, and an osteosarcoma in combination with an adenocarcinoma.

\section{Clinical Report}

A woman of 76 sought advice regarding a painless swelling in the left breast. She stated that it had been present for four months, and claimed that she had had no previous trouble with the breasts.

On examination she was a rather obese elderly 


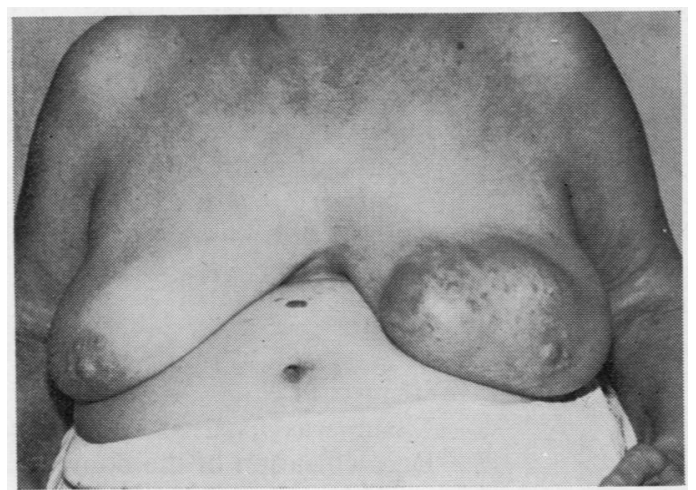

Fig. 1 Clinical photograph of the breast tumour. The pigmented lesions on the abdominal wall are seborrhoeic keratoses.

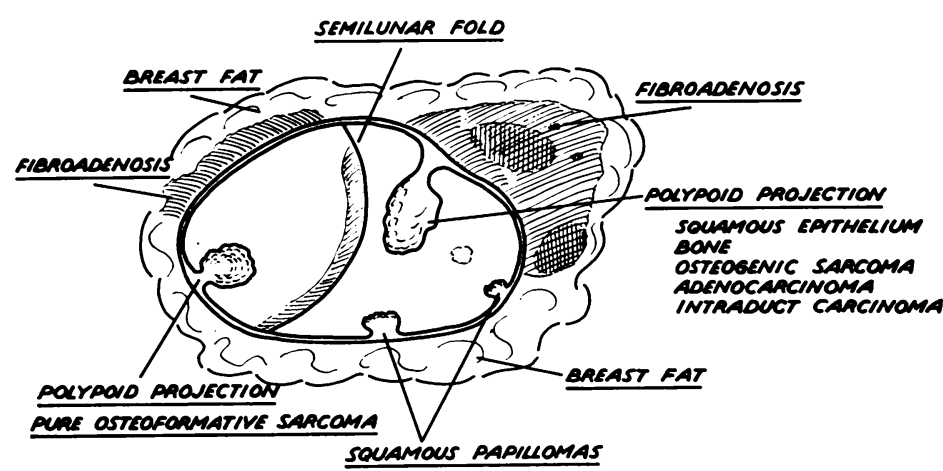

Fig. 2 Key diagram of the opened cystic tumour.

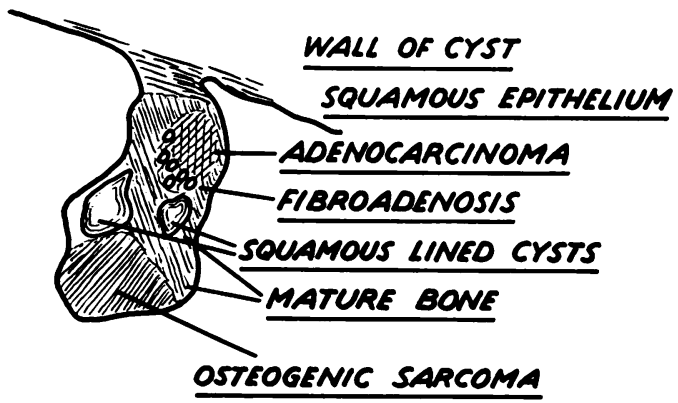

Fig. 3 Key diagram of the larger of the two pedunculated polyps.

woman. The left breast was the site of a multinodular mass about $12.5 \times 7.6 \mathrm{~cm}$ situated behind the nipple and extending over to the medial quadrant (Fig. 1). Lymph nodes were not palpable in the axillae or supraclavicular fossae. The overlying skin was adherent to the swelling and showed a bluish discoloration. The mass was

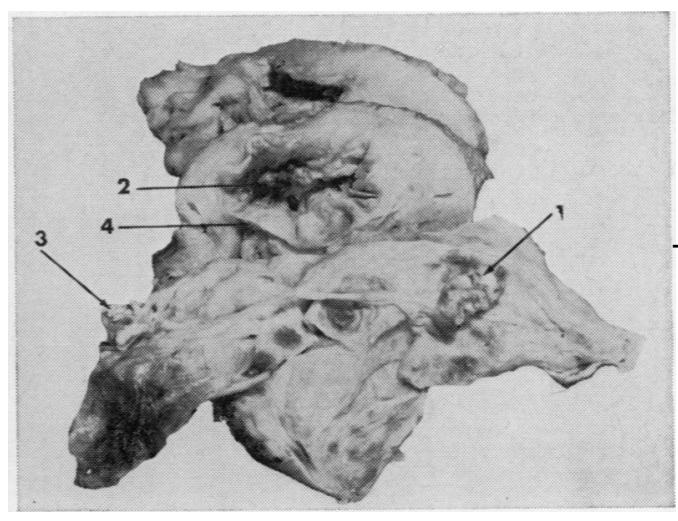

Fig. 4 The opened cystic tumour. The two pedunculated polyps (the larger, arrow 1; the smaller, arrow 2), the small white sessile growths (arrow 3), and the rigid, hard lining to the cyst (arrow 4) are clearly seen.

at the apex of a rather pendulous breast andwasc freely mobile on the chest wall.

She had gravitational ulcers on both anklest and a mild degree of uterine prolapse but was $\triangle$ otherwise apparently fit. A chest radiograph; showed slight cardiac enlargement and congestive changes in the lungs but no evidence of metastases.

OPERATION

A left simple mastectomy without axillary dis-ö section was performed on 30 October 1968.

The postoperative course was uneventful, the? wound healing satisfactorily, and the patient was discharged on the 25th postoperative day. 용

When seen for follow up at three and six months there was no evidence of recurrence and 3 . a radiograph showed no chest metastases.

\section{Pathology}

MACROSCOPIC APPEARANCE

The mass in the amputated breast proved to be a tense cystic tumour $10.0 \times 7.5 \times 5.0 \mathrm{~cm}$. One cutting into the tumour $200 \mathrm{ml}$ of dark brown viscous fluid escaped, revealing a unilocular cysto partitioned by a narrow semilunar fold on itsิ posterior wall. The cyst failed to collapse, having? a rigid wall which was extensively calcified. Twoo pedunculated polypoid nodules with greyish-white. irregular surfaces projected into the cavity of the cyst; the larger, $3.5 \times 1.5 \times 1.3 \mathrm{~cm}$, hanging from the roof, the smaller, $2.0 \times 1.8 \times 1.7 \mathrm{~cm}$, arising from the medial floor (Figs. 2 and 3). Both nodules were bony hard in consistency and ims possible to section with a knife. In addition five small, white sessile cauliflower growths were scattered on the cyst lining ranging in size from a few millimetres to $1.0 \mathrm{~cm}$ in diameter. The 


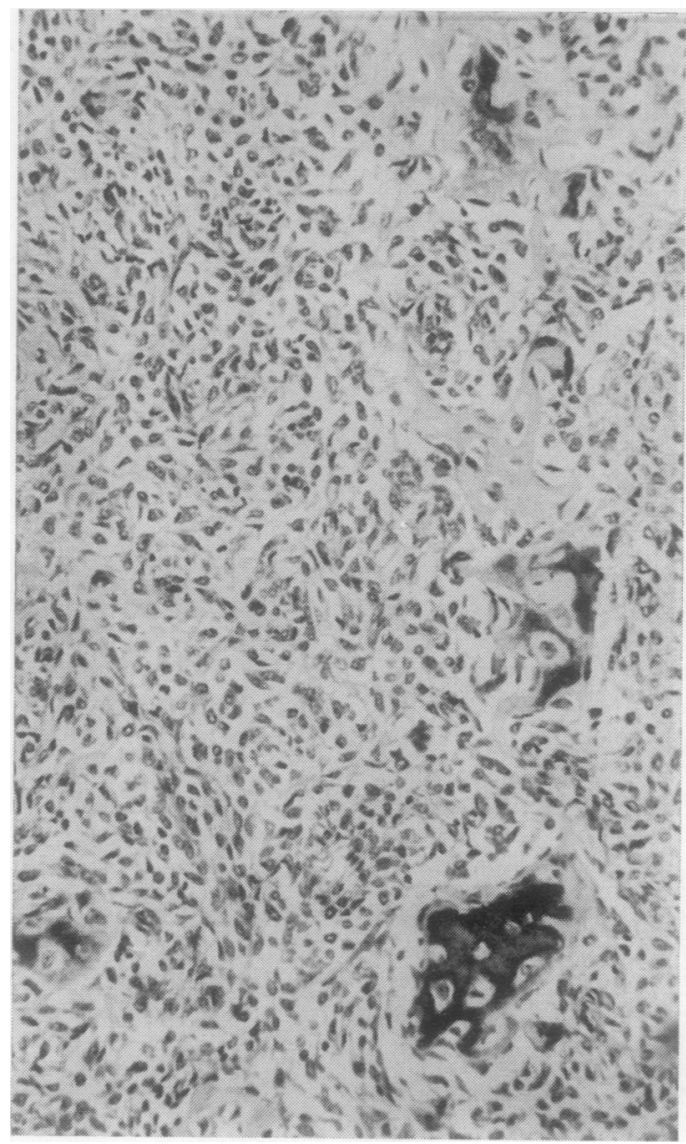

Fig. 5 Osteogenic sarcoma composing the structure of the smaller pedunculated polyp. Haematoxylin and eosin $\times 40$.

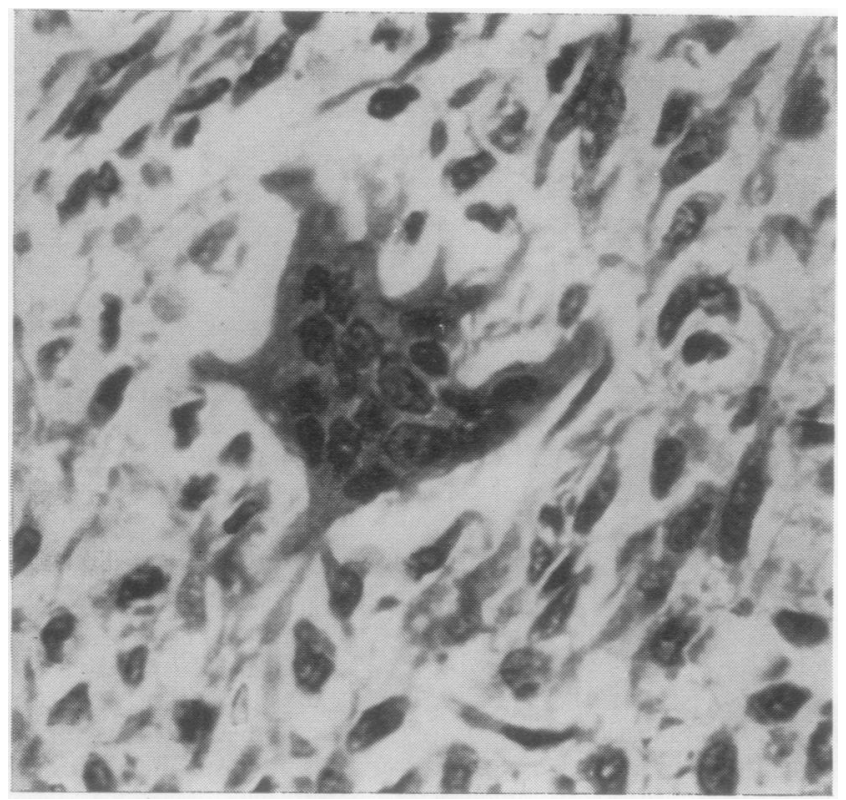

Fig. 6. Multinueleated giant cell-within the osteosarcoma. Haematoxylin and eosin $\times 400$. remainder of the cyst lining was smooth, whitean@ glistening (Fig. 4). Contiguous with the upper lateral pole of the cyst there was a solid area of fibrofatty breast tissue. Lymph nodes were nof identified in the specimen.

Numerous blocks were prepared from the cy $\overline{\overline{s i}}$ wall, the intracystic projections, and surrounding breast parenchyma.

\section{METHODS}

Tissue was fixed in $10 \%$ neutral formol-saline Decalcification of the bony areas was carried out in $5 \%$ nitric acid (stabilized with $0.1 \%$ urea Sections were stained with haematoxylin ang? eosin. The following special stains were als8 utilized: Masson's trichrome, Gordon and Sweet tid method for reticulin, alcian blue for mucopoly's saccharides, and Hale's colloidal iron techniques for acid mucopolysaccharides (with and without hyaluronidase).

\section{MICROSCOPIC APPEARANCE}

The main feature of the histology of this unusuad breast tumour was the varied mixture of tissue it contained.

The smaller of the intracystic bony nodules was composed entirely of malignant tumour histo logically indistinguishable from an osteosarcom of a well differentiated type (Fig. 5). The base of the nodule consisted of squamous epitheliun $\overrightarrow{\vec{D}}$ with an abrupt transition to a cellular strom $\vec{a}$ composed of a mixture of spindle and polyhedrat cells with hyperchromatic nuclei. Mitotic figures. were fairly numerous. Multinucleated giant cels of the type common in osteoclastoma were prominent (Fig. 6) and islands of osteoid an osseous material lay uniformly throughout the stroma (Fig. 7).

Sections of the larger, downwardly projecting nodule revealed a mosaic of benign and malignan tissues (Fig. 8). The base was again formed of regular non-keratinizing squamous epithelium merging abruptly into a stalk composed of mature bone with well formed trabeculae and a benign cellular fibrous stroma (Fig. 9). Embedded in thi\$્ટ stalk were two foci of undoubted adenocarcinoma. The adenocarcinoma was composed of irregula ducts, some crowded 'back to back' and sharing walls lined by a single cuboidal or columnaes epithelium and solid areas of pleomorphic cellso with little intervening stroma (Fig. 10). In parts there was an intracystic papillary structure (Fig. 11). Mitotic figures were numerous. Surroundin $\$$ this carcinoma were islands of mature squamous epithelium, a few small cysts with squamous epithelial linings, and the mature bone composin $\$$ the main tissue of the nodule (Fig. 12). At the apex, however, there was an abrupt transitio from benign-looking bone to malignant osteo formative tissue, the appearances being identical 


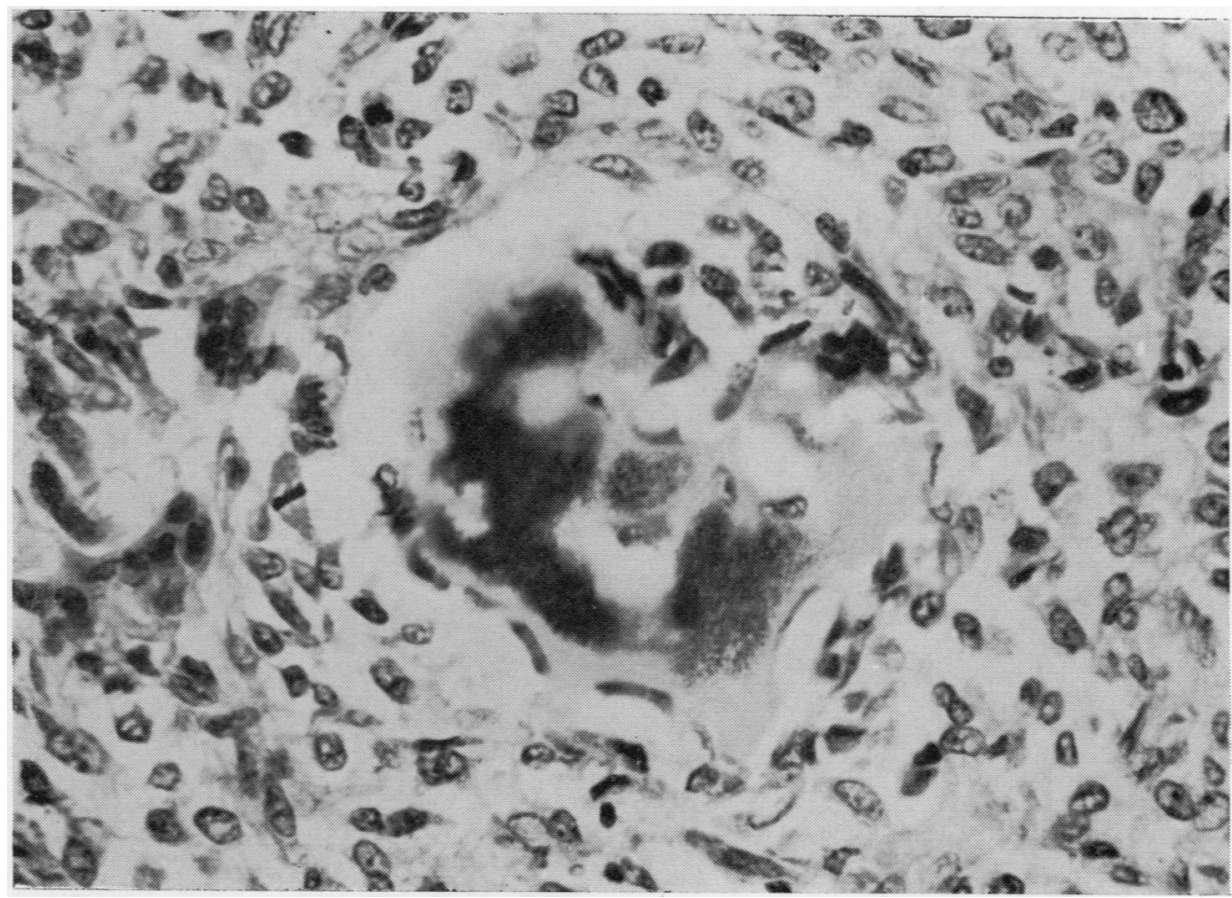

Fig. 7 Osteogenic sarcoma. Osteoid, bone, and mitotic activity are clearly seen. Haematoxylin and eosin $\times 400$.

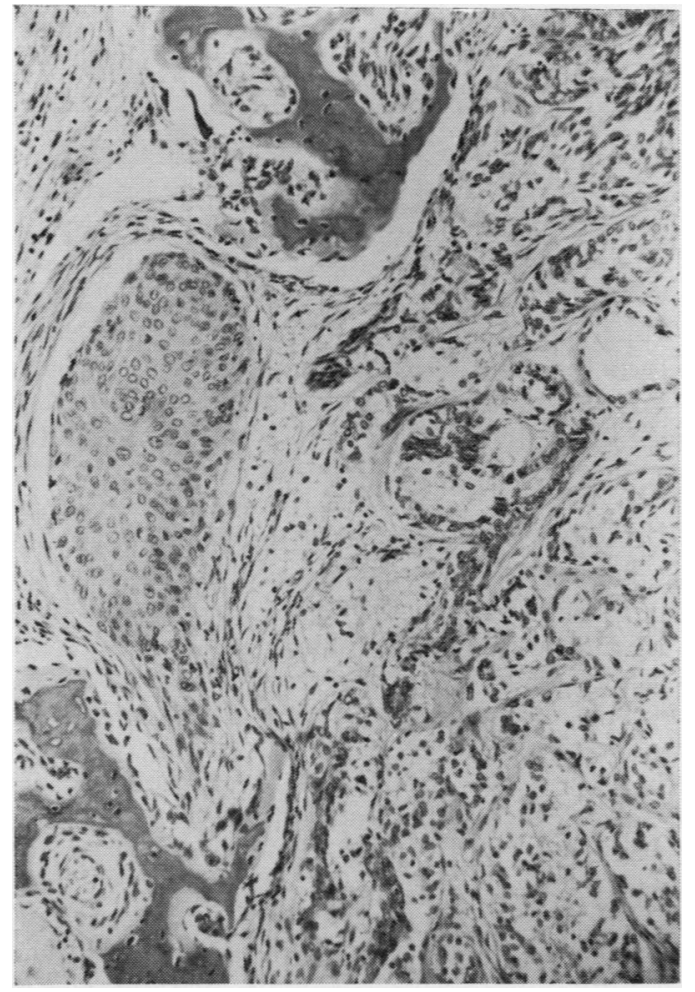

Fig. 8 An area of the larger pedunculated polyp displaying squamous epithelium, bone, and adenocarcinoma. Haematoxylin and eosin $\times 40$.

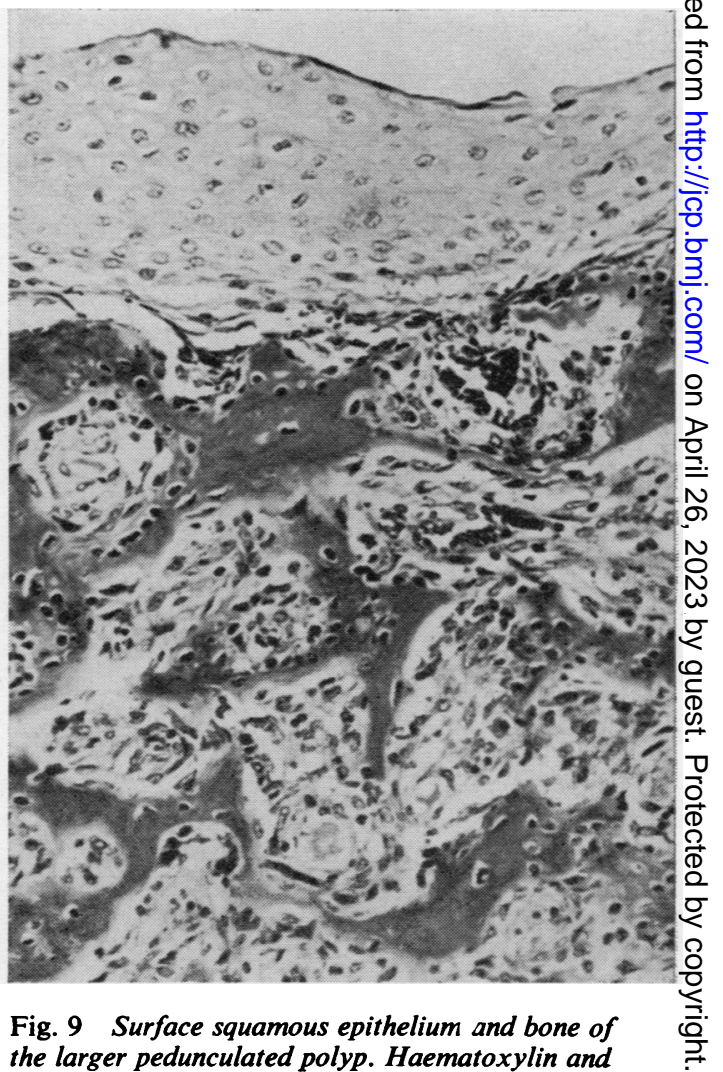

eosin $\times 140$. 


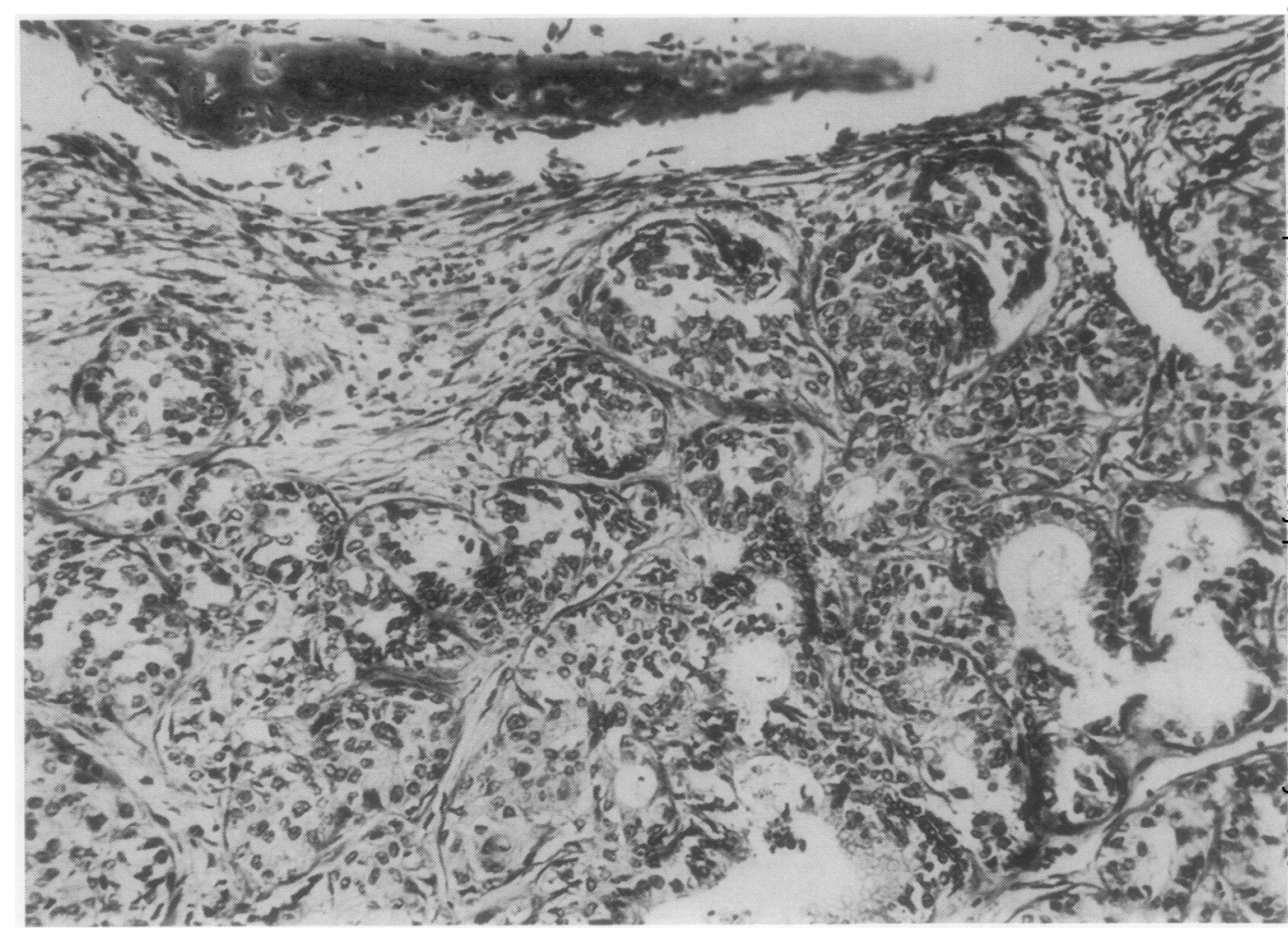

Fig. 10 Infiltrating adenocarcinoma and an area of bone within the larger pedunculated polyp.

Haematoxylin and eosin $\times 140$.

with the sarcoma in the companion but smaller projection (Fig. 13).

Sections from the cyst wall revealed dense fibrous tissue lined by non-keratinizing squamous epithelium which was continuous with the bases of the tumour projections and which became hyperplastic and papillomatous to form the small cauliflower excrescences noted in the gross specimen (Fig. 14). Beneath the lining epithelium were thin plaques of calcification and a few fragments of benign osteoid.

The tissue immediately surrounding the cyst consisted of compressed atrophic parenchyma. The dense fibrofatty area adjacent to the cyst showed florid fibrocystic disease-dilated ducts lined by hyperplastic epithelium (mild epitheliosis), duct papillomatosis, apocrine metaplasia, fibrosis, and chronic inflammatory cell infiltration. There was no microscopic evidence to suggest that the cystic tumour had originated in a fibroadenoma. There was no malignant tissue in the breast parenchyma outside the cystic tumour.

\section{Discussion}

Early in foetal life the parenchyma of the breast develops as a result of downward growth of finger-like epithelial processes from the overlying ectoderm. As the epithelial tracts progress and proliferate each extension becomes closely in 3 vested by a specialized connective tissue. This special relationship between epithelium ans mesenchyme can be seen during all the hormona $\bar{b}$ vicissitudes of mammary tissue and may also be demonstrated in the common benign patholo gical conditions of the breast.

Fibroadenosis with its multiplicity of micro N scopic features is undoubtedly the commonest pathological lesion of the human female breast Occasionally cyst formation may predominate $\omega$ The epithelial lining of such cysts most commonly undergoes pressure atrophy but on occasion proliferation, papillary formation, and evens intracystic carcinoma can be seen. That a relation:ship exists between fibroadenosis and breas 5 carcinoma is now accepted by most authoritiesD (Davis, Simons, and Davis, 1964) but any such? relationship between fibroadenosis and the less 0 common breast sarcoma has not been defined? However, a distinct relationship between the fibroadenoma and sarcoma is definintely estab? lished (Curran and Dodge, 1962). A fibroadenoma most commonly arising in the breast of the young? adult woman, may be considered as a local area 


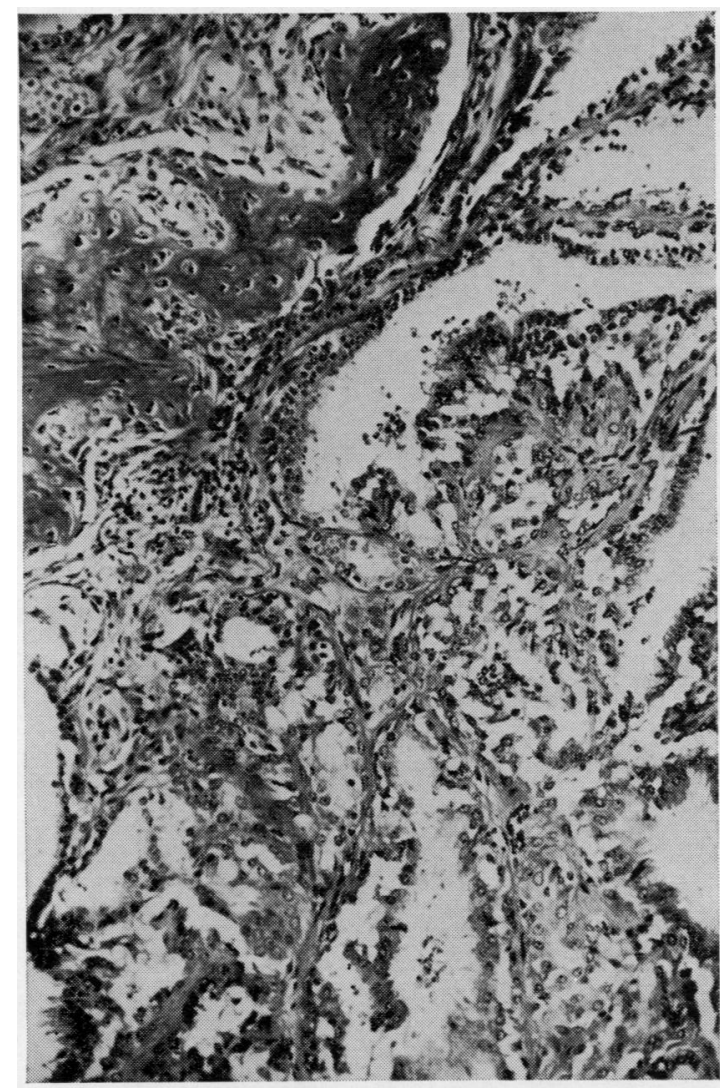

Fig. 11 Another area of adenocarcinoma displaying papillary formation. Haematoxylin and eosin $\times 40$.

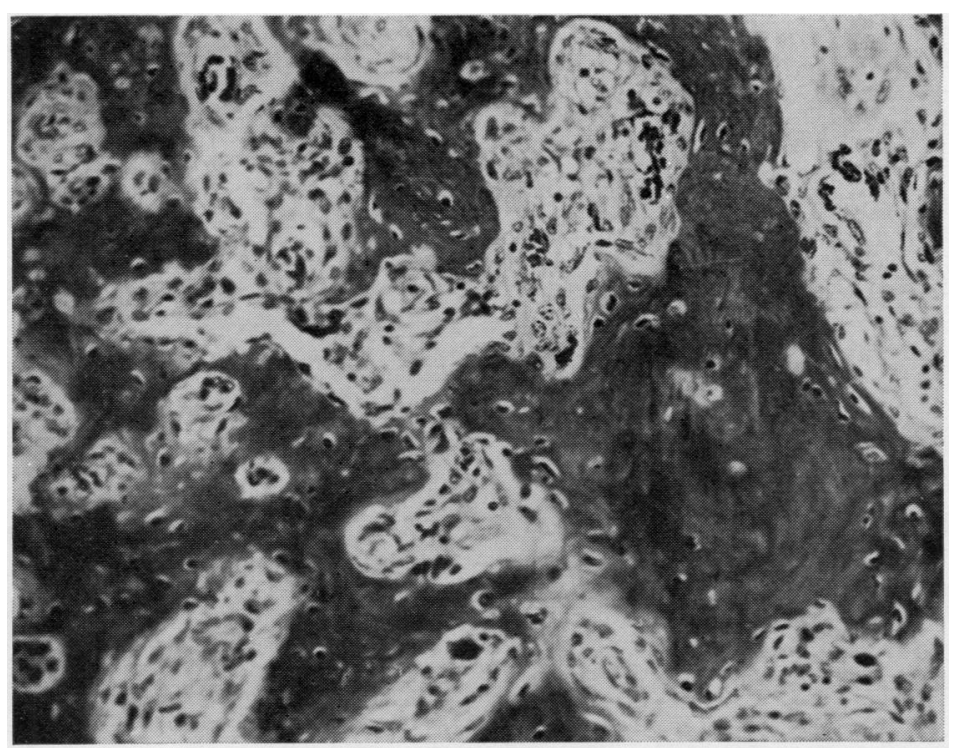

Fig. 12 The bone trabeculae composing the main structure of the larger pedunculated polyp. Haematoxylin and eosin $\times 140$. of mammary dysplasis which is possibly hormone ${ }^{c}$ dependent. When seen in the older woman such $\frac{\rho}{\bar{F}}$ growths are more likely to represent but one $r$ variant of a generalized picture of fibroadenosis $\stackrel{0}{\rightarrow}$ and therefore separation between fibroadenoma $\underline{0}$ and fibroadenosis is less clearly possible in this age group.

Giant fibroadenomas (benign cystosarcoma 읃 phyllodes) present most commonly in the elderly female. A history of recent rapid growth is often $\frac{0}{7}$ given by the patient and such a statement often $\stackrel{\varnothing}{\Omega}$ results in consideration of a malignant process although on microscopic examination the majority $\vec{\circ}$ of such tumours have a benign structure (Oberman, 1965a). The great percentage of giant $\vec{\omega}$ fibroadenomas have a solid macroscopic appear- $\rho$ ance with only occasional clefts separating the $\frac{0}{8}$ constituent lobules but occasionally the tumour is assumes a cystic form, the intra-canalicular pro- or jections of stroma and epithelium remaining as $A$ polypoidal projections into the cystic cavity. $\vec{A}$

That the stroma of a fibroadenoma may under- $\frac{}{3}$ go metaplasia to form heterologous tissue is well known (Robb and Macfarlane, 1958). Less well $\subseteq$ known is the fact that in rare instances the epithelial component may also undergo meta- $\overrightarrow{0}$ plasia to that of a squamous type (Salm, 1957; .

Willis, 1962).
Tumours of the canine (Fidler and Brodey, 1967) and feline breast (Schmidt and Langham, 1967) often show metaplasia of the stroma resulting in the formation of bone and cartilage $\stackrel{\mathbb{Q}}{\mathscr{Q}}$ (Allen, 1940; Willis, 1967). Such a phenomenon $\overrightarrow{\vec{P}}$ is rare in the human breast and when seen involves $\frac{3}{3}$ the stroma of benign or malignant fibroadenomas $\supset$ (Rottino and Howley, 1945; Willis, 1967). The histogenesis of osseous metaplasia in close approximation to epithelial tissues is poorly? understood (Collins and Curran, 1959) but may be seen in the gastrointestinal and genitourinary. tracts (Pang, 1958) and in certain tumours of the skin and salivary glands (Yates and Paget, 1952).

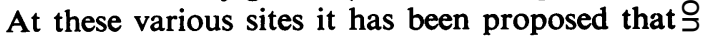
the epithelium acts as an 'organizer' in stimulating $>$ the surrounding mesenchymal cells to lay down bone. Experiments with transplanted urinary (Constance, 1954) and gallbladder epithelium have resulted in the formation of bone within the mesenchyme adjacent to the transplant (Huggins, $\omega$ 1931). In an attempt to relate this process to particular epithelial cells, Azzopardi and Smitho (1959), in their study of salivary gland neoplasms, proposed that the myoepithelial cell was res- + ponsible for the production of the connective $\frac{T}{T}$ tissue mucins in which bone could be formed. $\frac{}{\mathbb{D}}$

Occasionally giant intracanalicular fibro- $\frac{?}{\mathbb{D}}$ adenomas are found to be histologically malig- $\frac{\varrho}{0}$ nant (malignant cystosarcoma phyllodes), the mesenchymal component being most commonlyo implicated to form a spindle cell sarcoma. Stewart (1950) pointed out that 'a very smalko

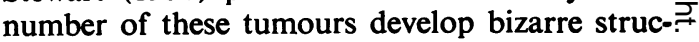




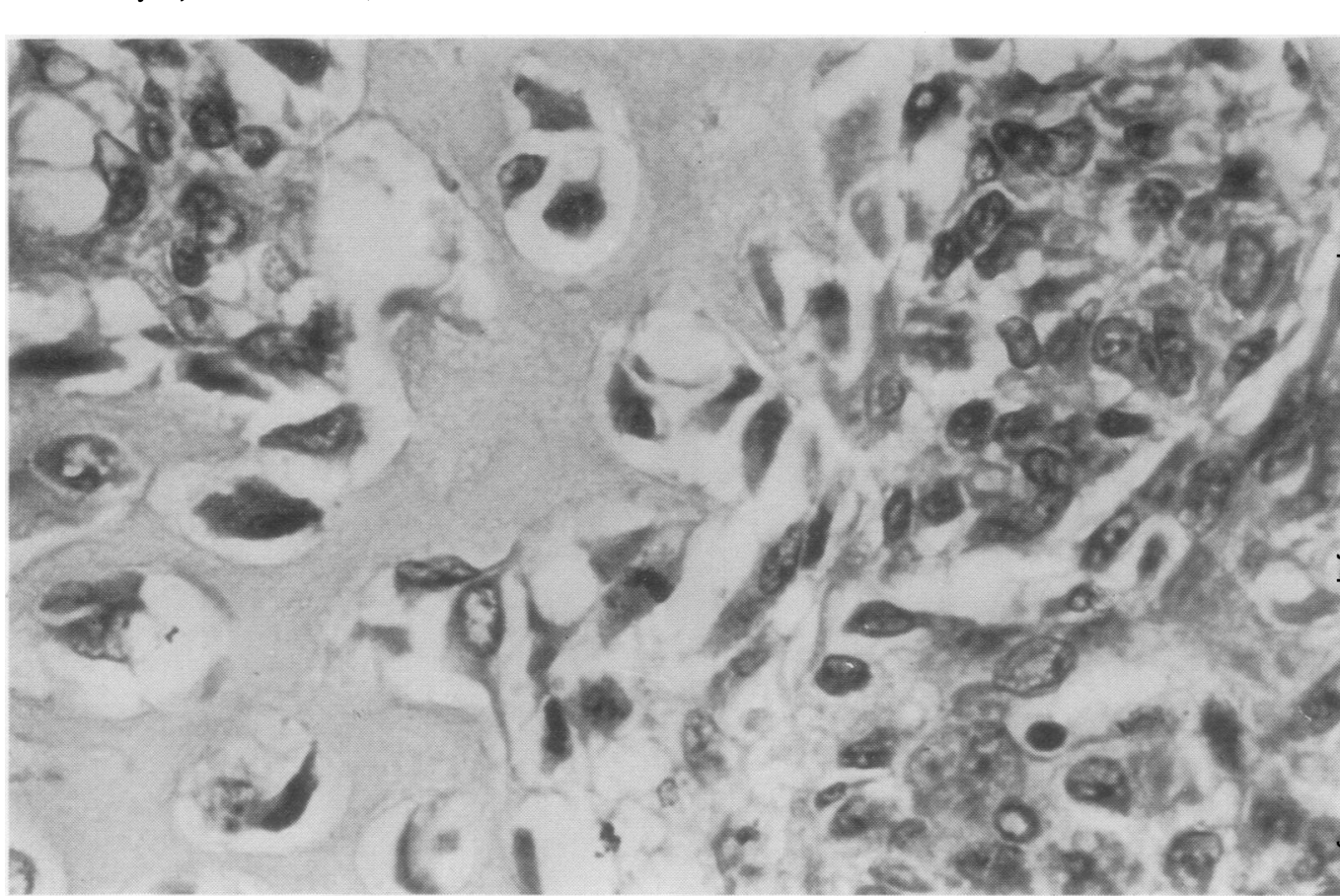

Fig. 13.

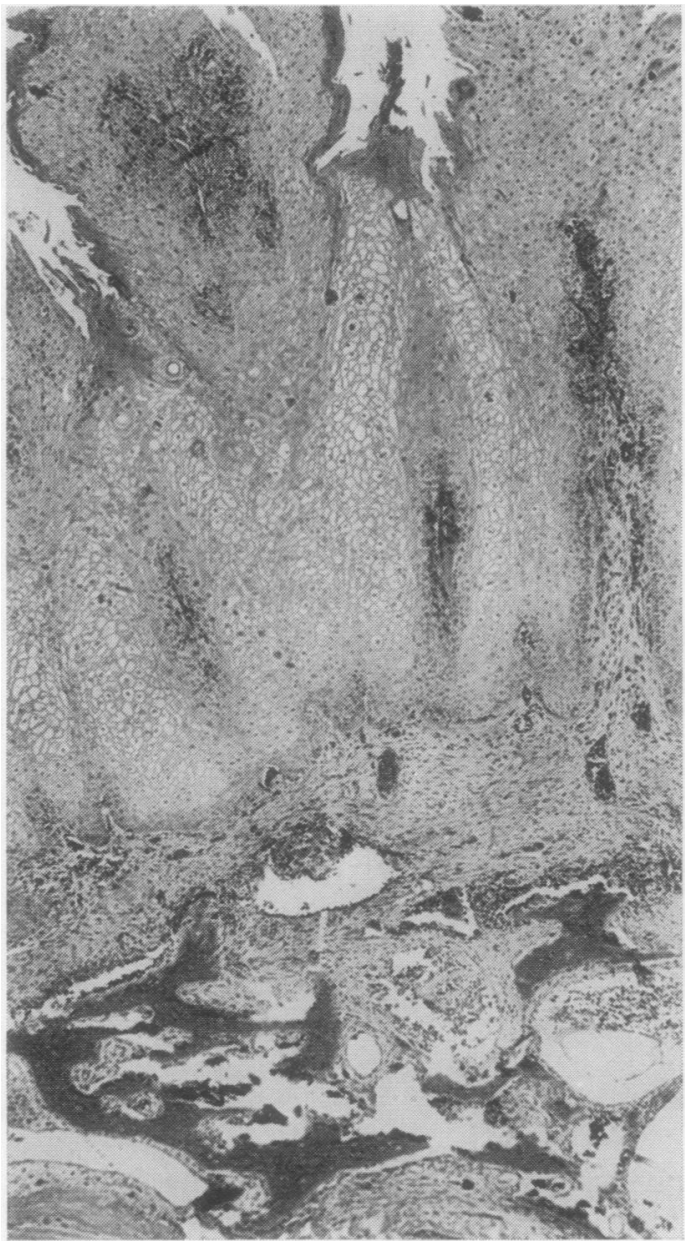

Fig. 13 Osteoid formation within an area of osteosarcoma seen in the larger polyp. Note the mitotic figure. Haematoxylin and eosin $\times 400$.

Fig. 14 The abundant squamous epithelium composing the small sessile 'cauliflower-like' excrescences Note the bone formation and the vascular channels in the underlying cyst wall. Haematoxylin and eosin $\times 40$.

tural patterns with the formation of atypical bon and cartilage' while Willis (1959) considers tha such metaplastic tissue may be malignant and form osteosarcomas, chondrosarcomas, an osteoclastomas.

The classification of breast sarcoma is a coñ fusing topic (Norris and Taylor, 1968). All authors accept the so-called 'pure' sarcomas as definite entities but it is in regard to the sarcomas cono taining an epithelial component where disagree ment exists. Botham, McDonald, and Clage (1958) considered that lesions containing an epithelial component intermixed with a richy cellular stroma should be excluded, while other workers (Oberman, 1965b; Lattes 1967) corg sidered that carcinomas associated with malige nant metaplasia of their surrounding stroma (composite tumours or combined tumours) Fig. 14. should also be excluded from any series of breast 
sarcoma. However, the majority of workers in this field accept the possibility of intermixture of components in mammary gland neoplasms, and, although there is no clear uniformity, the following categories of breast sarcoma are commonly listed:

\section{'PURE' SARCOMA}

These are (1) sarcomas not specifically related to mammary tissue, eg, malignant lymphoma; (2) sarcomas arising from general breast mesenchyme, eg, liposarcoma and haemangiosarcoma; (3) sarcomas not appearing to arise from fibroadenomas and having a uniform structure.

\section{COMPOSITE TUMOURS}

Sarcomas arising from a fibroadenoma, eg, malignant cystosarcoma phyllodes, are oiten composite tumours.

Certain authorities clearly separate sarcomas of the malignant cystosarcoma phyllodes type from the diffuse pure sarcomas not seen to arise from a fibroadenoma, for the former rarely metastasizes, thereby differing from the more aggressive pure sarcoma. However, in a number of instances it may not be possible to demonstrate such an origin owing to the destructive and invasive nature of the neoplasm (Fawcett, 1967).

The great majority of sarcomas of the breast occur in elderly women. They are extremely rare (Botham et al, 1958; Hill and Stout, 1942) and in a 10 -year period formed only $0.9 \%$ of all malignant breast tumours seen at one hospital (Curran and Dodge, 1962), and stromal sarcomas accounted for only $0.6 \%$ of 5,458 malignant breast tumours in the series of Kennedy and Biggart (1967). In regard to the sarcomas which have undergone metaplasia, the case described by Jernstrom et al (1963) was the only osteosarcoma in 3,309 malignant neoplasms of the breast collected in 18 years. It is clear, therefore, that osteosarcoma of the breast is a distinct rarity, and some authors (Lattes, 1967) do not accept such an entity and regard the examples of bone and cartilage formed by malignant tumours of the breast as probably carcinomas with osseous and cartilaginous metaplasia. Smith and Taylor (1969), in their recent series of 35 cases from the files of the Armed Forces Institute of Pathology, regard most of the heterologous bone and cartilage seen in breast tumours to arise from stromal metaplasia but also accept that certain adenocarcinoma cells may undergo direct transition to form bone- and cartilage-forming cells. Willis (1959) regards the majority of predominantly cartilaginous, bony and osteoclastic mammary tumours as metaplastic variants of the 'cystosarcoma' group and advocates their segregation as a subgroup of mammary sarcoma because of their relatively frequent malignancy.
When an adenocarcinoma develops jointly with $c$ a metaplastic breast sarcoma a most bizarre $\frac{\rho}{=}$ picture (Willis, 1967), as is seen in our present ${ }_{7}$ case, results. This intermixture of an epithelial and mesenchymal neoplasm must undoubtedly $\underline{\underline{O}}$ raise many difficulties in interpretation and in classification. It should be pointed out, however, $\stackrel{5}{\rho}$ that such composite or mixed malignant tumourso are commonly seen in the canine and feline breast $\underline{0}$ and metastases of both malignant elements have $\frac{\bar{s}}{\sigma}$ been described.

Hill and Stout (1942) postulated that there were three possible ways for a composite malignant ${ }^{\text {s }}$ tumour to develop: (1) malignant transformation? of an epithelial and a mesenchymal component $\overrightarrow{\vec{\omega}}$ of a teratoma; (2) a primary carcinoma inciting $\stackrel{\omega}{\omega}$ the surrounding stroma to malignancy; (3) a malignant stroma inciting the adjacent epithelium. in

Possibly a fourth postulate should be added to $i$ the above list which would explain the multiple changes seen in our present case. As indicated $\vec{A}$ earlier in this discussion, a close association? between epithelium and mesenchyme of the breast definitely exists and it seems not unreason- $\subseteq$ able to consider the possibility of an inciting agent inducing metaplasia and neoplasia of both com- $\overrightarrow{0}$ ponents simultaneously.

The prognosis of mammary tumours containing osteoid tissue remains conjectural due to the small number of cases seen in any one series. Rottino and Howley (1945) pointed out the danger of incomplete removal by local enucleation $\frac{\mathrm{D}}{\circ}$ techniques but considered that simple mastectomy was normally adequate because of the very low incidence of lymph node metastases.

References

Allen, A. C. (1940). So-called mixed tumours of the mammary gland of dog and man with special reference to the? general problem of cartilage and bone formation. Arch. 의 Path., 29, 589-624.

Azzopardi, J. G., and Smith, O. D. (1959). Salivary gland tumours 0 and their mucins. J. Path. Bact., 77, 313-140.

Botham, R. J., McDonald, J. R., and Clagett, O. T. (1958). D Sarcoma of the mammary gland. Surg. Gynec. Obstet., 음 107, 55-61.

Collins, D. H., and Curran, R. C. (1959). Pathological ossification $N$ and osseous metaplasia in man. In Modern Trends in Pathology, 1st series, edited by D. H. Collins, pp. 300-334. N Butterworth, London.

Constance, T. J. (1954). Localised myositis ossificans. J. Path. W Bact., 68, 381-385.

Curran, R. C., and Dodge, O. G. (1962). Sarcoma of breast with particular reference to its origin from fibroadenoma.J. clin. Path., 15, 1-16.

Davis, H. H., Simons, M., and Davis, J. B. (1964). Cystic disease $\mathscr{D}$ of the breast: relationship to carcinoma. Cancer (Philad.), $17,957-978$.

Fawcett, F. J. (1967). Sarcoma of breast. Brit. J. Cancer, 21, $\bar{O}$ 285-294.

Fidler, I. J., and Brołey, R. S. (1967). A necropsy study of canine $\stackrel{\overparen{D}}{?}$ malignant mammary neoplasms. J. Amer. vet. med. Ass., $\overparen{D}$ 151, 710-715.

Gonzalez-Licea, A., Yardley, J. H., and Hartmann, w. H. (1967). $\sigma$ Malignant tumor of the breast with bone formation Studies by light and electron microscopy. Cancer (Philad.), $\bigcirc$ 20, 1234-1247.

Hill, R. P., and Stout, A. P. (1942). Sarcoma of tbe breast. Arch. Surg., 44, 723-759.

Huggins, C. B. (1931). The formation of bone under the influence of epithelium of the urinary tract. Arch. Surg., 22, 377-408. 
Jernstrom, P., Lindberg, A. L., and Meland, O. N. (1963). Osteogenic sarcoma of the mammary gland. Amer. J. clin. Path., 40, 521-526.

Kennedy, T., and Biggart, J. D. (1967). Sarcoma of the breast. Brit. J. Cancer., 21, 635-644.

Lattes, R. (1967). Sarcomas of the breast. J. Amer. med. Ass., 201, 531-532.

Norris, H. J., and Taylor, H. B. (1968). Sarcomas and related mesenchymal tumors of the breast. Cancer (Philad.), 22, 22-28.

Oberman, H. A. (1965a). Cystosarcoma phyllodes. A clinicopathologic study of hypercellular periductal stromal neoplasms of breast. Cancer (Philad.), 18, 697-710.

Oberman, H. A. (1965b). Sarcomas of the breast. Cancer (Philad.), 18, 1233-1243.

Pang, L. S. C. (1958). Bony and cartilagenous tumours of the urinary bladder. J. Path. Bact., 76, 357-377.

Robb, P. M., and Macfarlane, A. (1958). Two rare breast tumours. J. Path. Bact., 75, 293-298.

Rottino, A., and Howley, C. P. (1945). Osteoid sarcoma of the breast: a complication of fibroadenoma. Arch. Path., 40, 44-50.

Salm, R. (1957). Epidermoid metaplasia in mammary fibroadenoma with formation of keratin cysts. J. Path. Bact., 74, 221-222.

Schmidt, R. E., and Langham, R. F. (1967). A survey of feline neoplasms. J. Amer. vet. med. Ass., 151, 1325-1328.
Shapiro, R., Reichman, L., Getzoff, C., and Weiss, A. (1967) Osteosarcoma of breast metastasing to the oral cavity Oral Surg., 23, 58-61.

Smith, B. H., and Taylor, H. B. (1969). The occurrence of boned and cartilage in mammary tumors. Amer. J. clin. Path $51,610-618$

Stewart, F. W. (1950). Tumors of the breast. Atlas of Tumo으. Pathology, Sect. IX, Fasc. 34, p. 66. Armed Forces Institute of Pathology, Washington.

Tudhope, G. R. (1939). A complex malignant mammary tumour J. Path. Bact., 48, 499-506.

Willis, R. A. (1958). Squamous-cell mammary carcinoma of predominantly fibrosarcom?-like structure. J. Path. Bact 76,511-515.

Willis, R. A. (1959). Mammary tumours. In Modern Trends if Pathology, 1st series, edited by D. H. Collins, p. ${ }^{108}$
Butterworth, London.

Willis, R. A. (1962). The Borderland of Embryology and Pathology, 2nd ed., p. 523. Butterworth, London.

Willis, R. A. (1967). Pathology of Tumours. 4th ed., pp. 212, 219and 703-704. Butterworth, London.

Yates, P. O., and Paget, G. E. (1952). A mixed tumour of salivaros gland showing bone formation, with a histochemical study of the tumour mucoids. J. Path. Bact., 64, 881-888. 